\title{
Consideration on Local Heat Transfer Measurement of Plate Heat Exchanger with the Aid of Simulation
}

\author{
Thiha Tun ${ }^{\mathrm{a}, *}$, Keishi Kariya ${ }^{\mathrm{b}}$, Akio Miyara ${ }^{\mathrm{c}}$ \\ ${ }^{a}$ Graduate School of Science and Engineering, Saga University. Email: michaellin630@ gmail.com \\ ${ }^{b}$ Department of Mechanical Engineering, Saga University. Email: kariya@me.saga-u.ac.jp \\ ${ }^{\mathrm{c}}$ Department of Mechanical Engineering, Saga University. Email: miyara@me.saga-u.ac.jp
}

\begin{abstract}
In this study, the local heat transfer coefficient of boiling and condensation were obtained by an experimental set up using vertical stainless-steel type brazed plate heat exchanger. A series of 8 vertical brazed plates are used as the major components of the test section of experimental set up and are fabricated into layers so that flow channels are formed between the plates through which water and refrigerants are flowing through. The experiments are carried out at the mass flux of 10,20 and $50 \mathrm{~kg} /\left(\mathrm{m}^{2} \cdot \mathrm{s}\right)$. In order to measure the local heat transfer coefficient, flat stainless-steel plates of $10 \mathrm{~mm}$ in thickness are installed attached to the vertical plates onto which the thermocouples are positioned to measure the temperature distributions at the surface of the plates. By performing the experiment, the direction of the heat flux across the plate tends to deviate downward especially at the lower part of the plate due to the non-uniform temperature distributions across the plate. The results are analyzed and validated at the mass flux of $10 \mathrm{~kg} /\left(\mathrm{m}^{2} \cdot \mathrm{s}\right) \mathrm{by}$ the aid of the simulation tool by using ANSYS FLUENT 19.1 to estimate the local heat transfer coefficient and the heat flux across the plate. The analysis result shows that the simulation model can assist to track the deviation of the direction of the heat flow from the horizontal direction across the plate and the experimental results of the local heat transfer coefficient have similar trends with that of the simulation results.
\end{abstract}

Keywords: Boiling; condensation; local heat transfer coefficient; plate heat exchanger; refrigerant

\section{Introduction}

Plate heat exchangers (PHEs)which have an advantage in acquiring larger heat transfer per volume are highly applicable in industrial applications such as refrigeration, heating, cooling, chemical processing, etc [1]-[4]. Additionally, PHEs have benefits in reducing refrigerant charge and lighter structural supports [5], [6]. The structural construction of the PHEs basically consist of a series of thin, rectangular, pressed steel plates which are stacked and pressed together such that several channels are formed between the plates [7], [8]. The formed channels have been alternate passages for hot and cold fluid media streams to exchange heat between the two fluids [1]-[4]. Since PHE generally has larger heat transfer surface area than a shell and tube type heat exchangers, they are widely used in in many industrial and domestic applications in the small to medium size range [9]. Bergles et al. and Kakaç et al. have mentioned that PHEs have the ability in a flexibility in adding and removing the plates for accommodating variable heat loads, capable of variations in geometry and cleanability (e.g. the gasketed-PHE). Several types of plate heat exchangers are applicable,

${ }^{*}$ Corresponding author. Tel.: +8-191-097-292

Graduate School of Science and Engineering, Department of Mechanical Engineering

1Honjo-machi, Saga-shi, 850-8502, Japan depending on the industrial application. Mainly, plate heat exchangers: gasketed, brazed, welded/semi-welded and shell and plate are categorized into four types in many industrial applications. Brazed plate heat exchangers are compactable and exhibit high performance in heat transfer capability, and for these reasons brazed PHEs are suitable in heating and refrigerating applications such as evaporation or condensation of refrigerants, heat pumps and cooling of water or oil circuits in engines [10]-[12]. They provide higher resistant to corrosion due to the combination of the stainless-steel plates with the copper brazing and can withstand quite high pressures as all the local contact points between the corrugations in the stack are brazed [13]-[16]. On a contrary, the brazed type PHEs cannot be disassembled for cleaning purpose, and thus the application in fouling are limited [17]-[20].

In this study, a brazed type PHE with corrugation angle of $60^{\circ}$ were used in the specially fabricated test section. The refrigerant R1234yf and water were used as the two operating fluid media. The experiment was carried out and the heat flux across the plate and the heat transfer coefficient on the surface of the PHE was estimated through the measurement points along the plates. The experimental results were analyzed with the aid of the simulation model implemented in ANSYS FLUENT 
19.1R1. The input boundary conditions of the simulation model were used from the experimental data and the heat fluxes across the plate and the local heat transfer coefficients of the experimental results were validated with the simulation results. By the assistance of the simulation model, the heat fluxes across the plate tends to deviate downwards at the lower part of the plate can be seen more clearly. And the validation results show that the experimental results and the simulation results undergo the similar trends at the selected measurement points with more or less deviations in the values of heat fluxes across the plate and the local heat transfer coefficient.

\section{Experimental Setup and Procedure}

The test section consisted of 8 brazed plates is connected to the primary loop through which the refrigerant of R1234yf is circulated by a micro pump. The refrigerant flow rate is adjusted by the rotation speed of the micropump. The inlet hose of the test section is connected to the pre-heater and the after condenser is located at the outlet hose of the test section so that the heated refrigerant from the pre-heater and the test section can be cooled down to the desired sub-cooled conditions before returning back to the circulated pump.

Water is used as pre-heater, after condenser, reservoir, and test section as heat source water in a separate loop. Coriolis flow meter and flow control valve are used as auxiliary equipment to monitor and control the refrigerant flow. After the mass flow rate is measured by the meter, it is heated by the pre-heater, the pressure and temperature are measured by the mixer, and then enters the test section. In addition, the data logger (Keithley Instruments Co., Ltd. switching function) is used to read the output values of thermocouples, pressure transducers, and Coriolis flow meters. The schematic diagram of the experimental set up has been shown in Fig. 1.

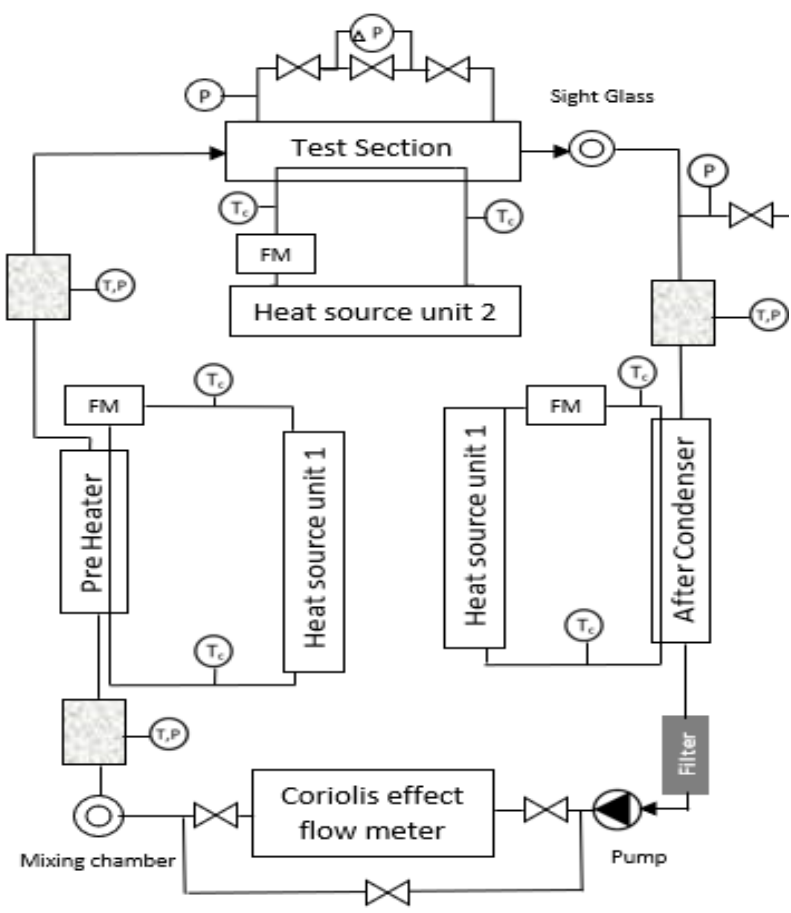

Figure 1. The measurement points distributions of the plate

\subsection{Information on test section and measurement procedure}

The test section, 8 plates in total, are stacked and held together by pressure plate while the refrigerant is flowed into the channel formed by the clearance between the two plates among the plates. The water is forced to flow through the channels lied at the outer sides of the two plates so that the two plates become a heat transfer medium during the process of heat exchange between the two different fluids. A pressure transducer is installed in the test section to monitor the differential pressure between the inlet and outlet of the test section and the overall pressure drop of the test section. In order to measure the local heat transfer coefficient of the heat exchanger plates, 20 thermocouples are set and attached to the surface of the plates to record the temperature distributions at the surface of the plates for both the refrigerant and the heat source water sides of the plates. The measurement points where the thermocouples are set are shown in Fig. 2. The temperature values obtained by the thermocouples are used to calculate the heat flux across the plate and the local heat transfer coefficients.

Table 1 show the geometry of the test section. The dimensions of the plate are $186 \mathrm{~mm}, 84 \mathrm{~mm}$, and $5 \mathrm{~mm}$ respectively. The corrugations pitch, depth and chevron angle are $5.6 \mathrm{~mm}, 1.5 \mathrm{~mm}$ and $60^{\circ}$ respectively. The length between the inlet and outlet port center is $136 \mathrm{~mm}$. The locations of the temperature measurement points are located at $14.75,36.75,58.75,80.75$, and $102.75 \mathrm{~mm}$ vertically from the inlet port of the plate. The horizontal arrangements of the measurement points can be seen in the Fig. 2.

Since the heat flux across the plate and the local heat transfer coefficient cannot be achieved directly from the experimental set up, the data reduction method is used to calculate the heat flux and the local heat transfer coefficient of the plate based on the temperature recorded by the thermocouples.

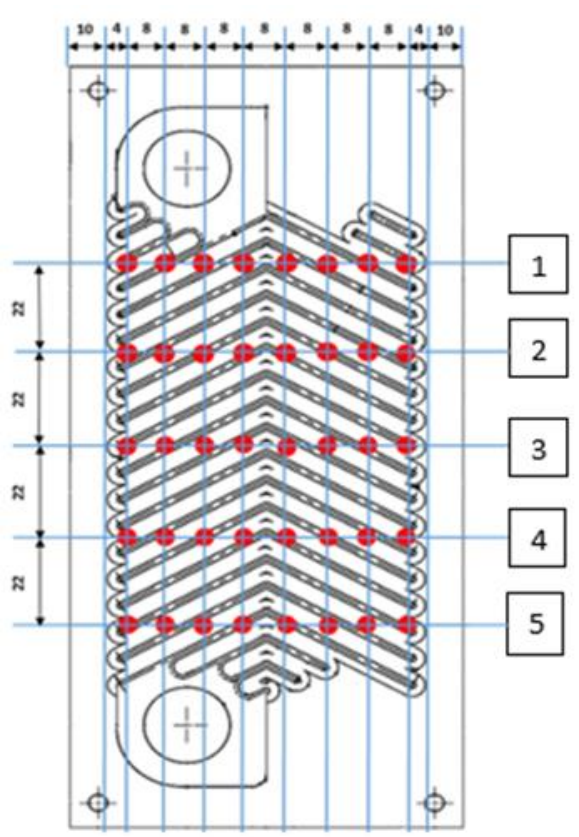

Figure 2. The locations of the measurement points on the plate 
Table 1 . Geometry and dimensions of the plate

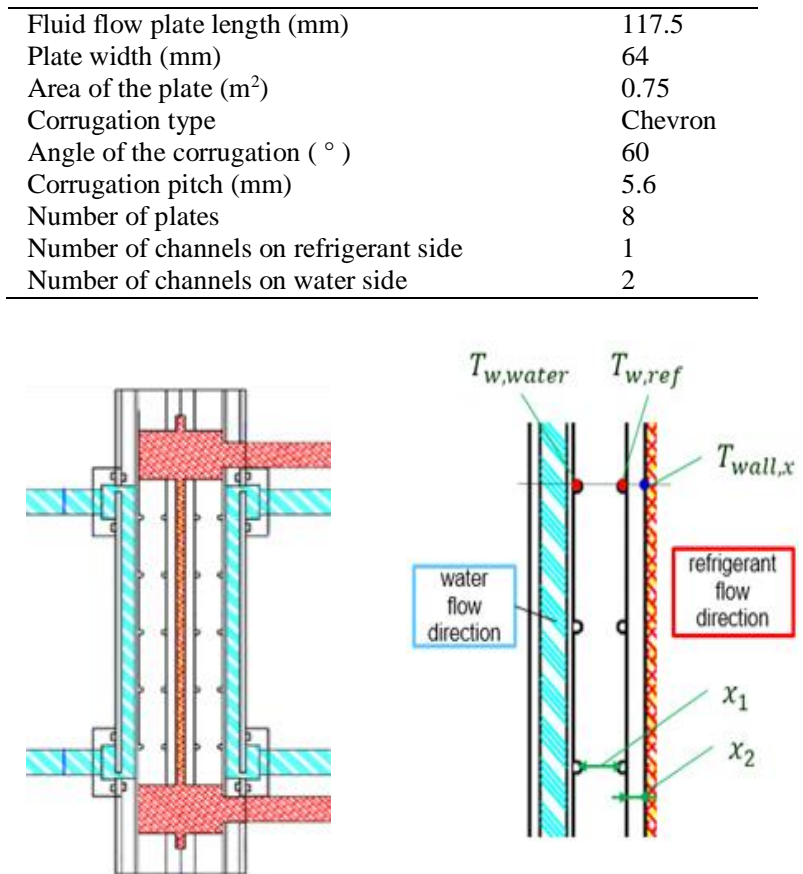

Figure 3. The section view of the test section for the data reduction method calculation

\subsection{Data reduction method}

Consider the process as the steady state onedimensional heat conduction, the data reduction method is initiated by the governing equation of the conduction heat transfer.

$$
\frac{\partial T}{\partial t}+\frac{\partial}{\partial x}\left(\lambda \frac{\partial T}{\partial x}\right)=0
$$

In the conduction heat transfer, the time derivative becomes neglected for the steady state process and the heat flux across the plate in one-dimensional heat transfer $\left(q_{x}\right)$ is

$$
q_{x}=\lambda\left(\frac{T_{w, r e f}-T_{w, w a t e r}}{x_{1}}\right)
$$

Because of the unavailability of the measurement of the wall surface temperature at the refrigerant side $\left(T_{w, r e f}\right)$, the wall temperature at the refrigerant side is calculated by the following equation.

$$
T_{w a l l, x}=T_{w, r e f}+\left(\frac{q_{x} x_{2}}{\lambda}\right)
$$

By using the value of the wall surface temperature $\left(T_{\text {wall }, x}\right)$, the local heat transfer coefficient, the heat flux per temperature difference $\left(\alpha_{x}\right)$, can be calculated.

$$
\alpha_{x}=\frac{q_{x}}{T_{\text {sat }}-T_{\text {wall }, x}}
$$

\section{Simulation Model and Procedure}

Although the heat flux and the local heat transfer coefficient can be calculated based on the experimental data, some important characteristics such as the behavior of the temperature distributions at and across the plate and

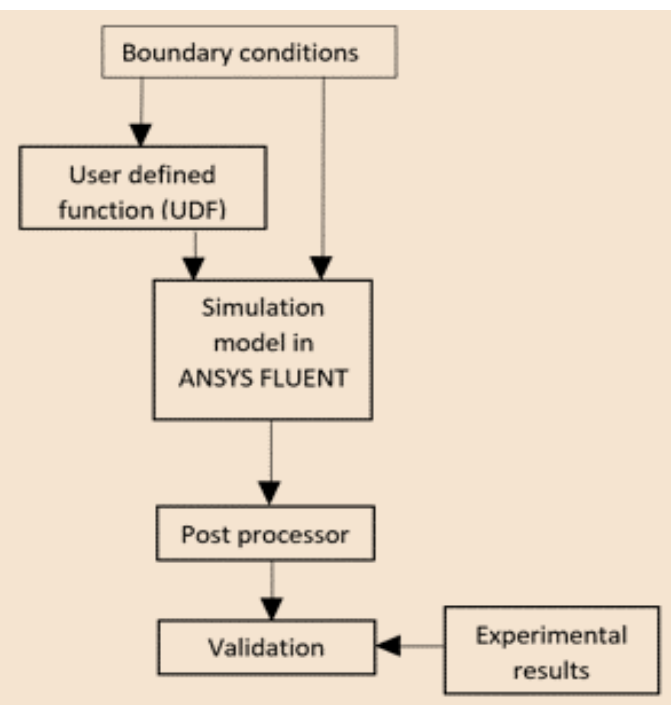

Figure 4. The schematic diagram of the simulation model

\section{Input temperature values at the water} side

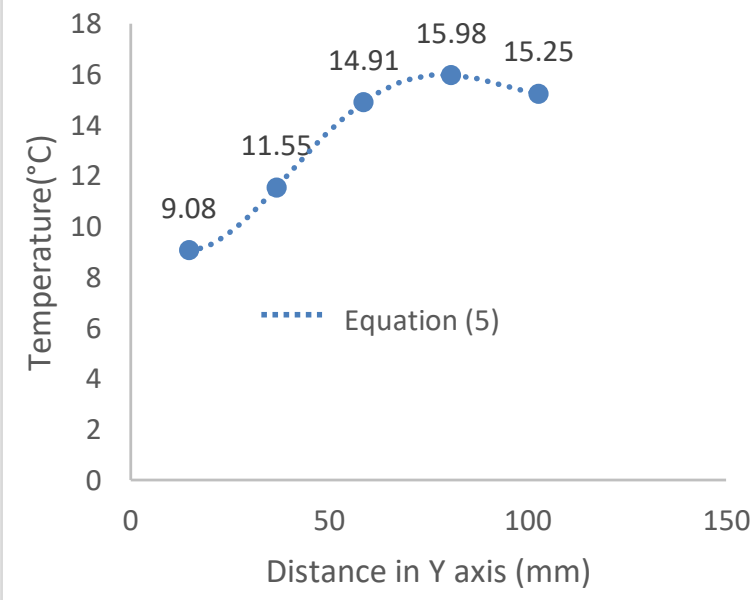

Figure 5 . The boundary condition for the water side

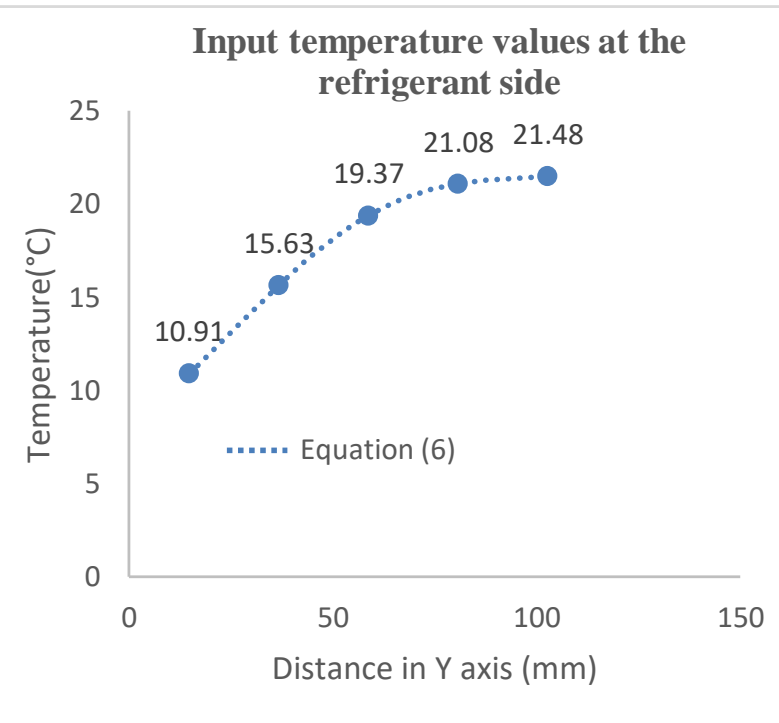

Figure 6 . The boundary condition for the refrigerant side 
heat flux across of the plate, cannot be evaluated by experimental work alone. For this reason, a simulation model is implemented in ANSYS FLUENT19.1R1. By the assistance of the simulation model, a more detail analysis can be carried out due to the isothermal lines and the directional vectors of the heat flux across the plate. Additionally, the experimental results can also be validated by the results evaluated from the simulated model. Figure 4 illustrates the plans and procedure of the simulation model.

The assumption of the input boundary condition for the simulation model is as follows

- Steady state condition

- No external energy exchange with the surrounding (no external work, no radiation heat absorption)

- Corrugation effect is neglected

- The model is simulated only at the portion where the measuring points are located (i.e.,14.75 to $102.75 \mathrm{~mm}$ vertically), and the top and down end sides of the plate is assumed to be adiabatic walls.

- Stainless steel with the thermal conductivity of $16.7 \mathrm{~W} /(\mathrm{mK})$ is used as material properties.

A set of temperature values were set at the surface of the wall based on the experimental results at the mass flux of $\mathrm{G}=10 \mathrm{~kg} /\left(\mathrm{m}^{2} \mathrm{~s}\right)$ according to the following functions shown in Figs. 5 and 6.

The input boundary condition at the water side was represented by the following function.

$$
\begin{gathered}
T(x)=7.0 \times 10^{-7} x^{4}-0.0002 x^{3}+0.0145 x^{2} \\
-0.3215 x+11.186
\end{gathered}
$$

The function mentioned below was applied at the refrigerant side.

$$
\begin{array}{r}
T(x)=3.0 \times 10^{-7} x^{4}-5 x^{3}+0.0047 x^{2} \\
+0.1073 x+8.5297
\end{array}
$$

The boundary conditions at the water and refrigerant sides were scripted in C programming language and imported to ANSYS FLUENT 19.1R1 as user defined functions (UDF).

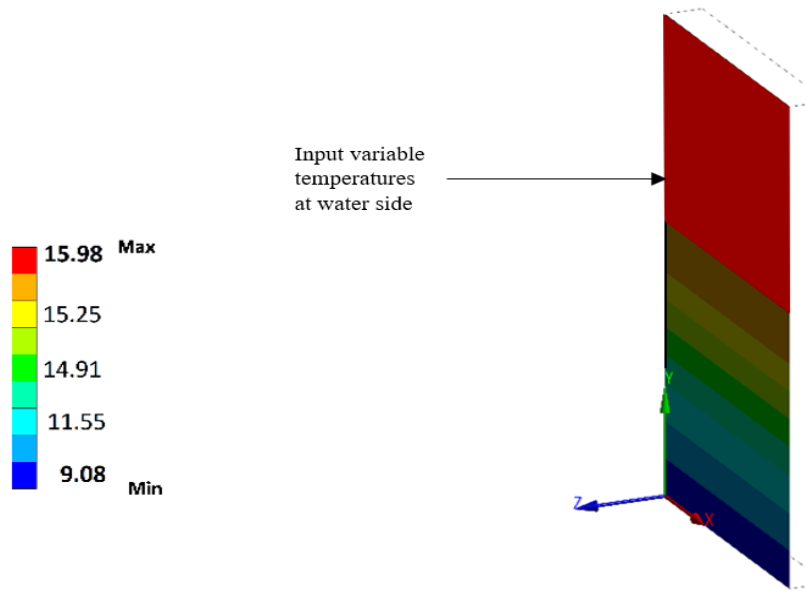

Figure 7. User defined function for the water side

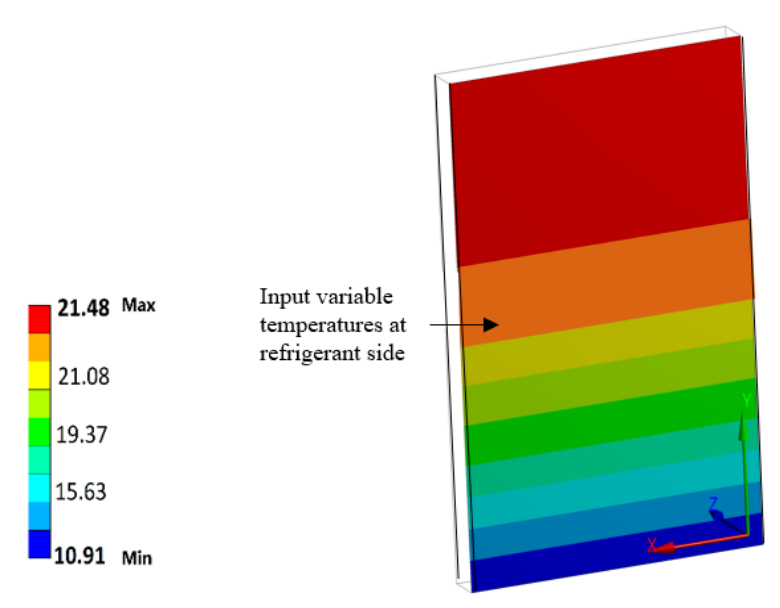

Figure 8. User defined function for the refrigerant side

\section{Results and Discussions}

With the boundary conditions mentioned above, the temperature distributions and the heat flux were calculated and the local heat transfer coefficient for the condensation mode at the mass flux of $10 \mathrm{~kg} /\left(\mathrm{m}^{2} . \mathrm{s}\right)$ by the ANSYS simulation model and then the validation of the experimental and the simulation results are carried out.

\subsection{Contour plot of the temperature distributions of the plate}

The directions of the refrigerant and the water was arranged in counter flow with heated water in downward direction and condensing refrigerant flowing downward. Since the heat exchange occurs between the refrigerant and water, the temperature at the water side increased with respect to the travelling distance in vertical direction with the maximum temperature of $15.25^{\circ} \mathrm{C}$ at the first row of the measuring points at the top side of the plate and the minimum temperature of $9.08^{\circ} \mathrm{C}$ at the bottom. Whereas, the refrigerant with the temperature of $21.48^{\circ} \mathrm{C}$ at the measurement point 1 , rejected heat gradually when flowing in the downward direction and flowed out with the minimum temperature of $10.91^{\circ} \mathrm{C}$ from the bottom side. Due to the unequal, non-uniform temperature distributions at the refrigerant and the water side and the lower temperature values at the lower sides of the plate, the isothermal lines are distributed in more or less inclinations across the plate which can be seen in Fig. 9(b). The slopes of the isothermal lines is steeper at the upper side of the plate than the lower side of the plate because of the temperature elevations of the refrigerant side and the water side at the upper side of the plate is larger than that of the elevations of the two sides at the lower side of the plate.

\subsection{Contour plot of the total heat flux across the surface of the plate and the heat flux in $x$ - and $y$ - components}

As the direction of heat flux is perpendicular to the isothermal lines, the total heat flux across the plate flow more or less horizontally from the refrigerant side to the water side at the upper side of the plate, while at the lower side of the plate, the directions of the total heat flux deviate from its horizontal direction and flow downward from the 
refrigerant to water side. The magnitude of the maximum total heat flux occurs at the topmost side of the plate with a value of $11.8 \mathrm{~kW} / \mathrm{m}^{2}$ and on the other hand, the minimum total heat flux of $1.36 \mathrm{~kW} / \mathrm{m}^{2}$ appears at the opposite bottommost part at the lower side of the plate. Since the directions of the total heat flux varies gradually from the upper side of the plate with more or less horizontally to the lower side pointing toward the downward directions, the magnitudes of the heat flux in $x$-component, $\left(q_{x}\right)$ have a higher values at the upper side of the plate than the lower side of the plate. The maximum value of the heat flux in the direction of $x$ axis is $11.104 \mathrm{~kW} / \mathrm{m}^{2}$ at the uppermost side of the plate as shown in Fig. 10. The minimum $x$ component heat flux lies at the bottom edge boundary between the refrigerant side and the adiabatic wall with the value of $-612.79 \mathrm{~kW} / \mathrm{m}^{2}$.

The negative value of the hat flux in $x$ component show that there is a small amount of heat flowing back to the refrigerant side in $x$ direction. In opposite to the heat flux in $x$ component, the values of the heat flux in $y$ direction increases from lower values to the higher values form the upper part to the lower part of the plate. The negative values of the $y$ component heat flux mean that the $y$ component heat flux have a direction opposite to the $y$ axis, i.e., the heat flux tends to flow in the downward direction at the lower part of the plate. The maximum magnitude of $\mathrm{q}_{\mathrm{y}}$ is $0.5012 \mathrm{kw} / \mathrm{m} 2$ at the top upper regions of the plate at the water side and the value of $85.633 \mathrm{~W} / \mathrm{m} 2$ at the upper parts of the refrigerant side. The maximum values of $\mathrm{q}_{\mathrm{y}}$ can be found at the lower region of the refrigerant side with the magnitude of $-3.2398 \mathrm{~kW} / \mathrm{m} 2$ in downward direction opposite to the $y$ axis.

\subsection{Validation of the experimental results and the simulation results}

The validation is carried out at the front and sides of the plate. The horizontal directional heat flux $\left(\mathrm{q}_{\mathrm{x}}\right)$ at the left and right sides of the plates are calculated by the data reduction methods in Eq. (2) by using the temperatures obtained experimentally. And the obtained heat flux at the sides are compared with the directional heat flux $\left(\mathrm{q}_{\mathrm{x}}\right)$ from the simulation model. The comparison results show that both the simulation and experimental results show the similar trends at both the left and right sides of the plate but the maximum heat flux of the simulation results is lower than the experimental results with the deviation of $4.7 \%$ at the left side and of $4.7 \%$ at the right side of the plate respectively. The experimental local heat transfer coefficients at the front face of the plate is calculated based on the Eq. (3) and for the simulation model, the local heat transfer coefficients are calculated at the ANSYS FLUENT post processor based on the horizontal directional heat flux $\left(\mathrm{q}_{\mathrm{x}}\right)$.

The comparison for the local heat transfer coefficients are proceeded at the measurement points shown in Fig. 2. The comparison results show that the values of the heat transfer coefficients are higher at the middle of the plate than at the two edges for both simulation and experimental data. And the overall trends at the measurement points results in higher values for the experimental data than the simulation data as the directional heat flux calculated by the experimental setup results in higher values than that of the simulation model. The experimental data recorded the peak value of the local heat transfer coefficient of $2.05 \mathrm{~kW} /\left(\mathrm{m}^{2} \mathrm{~K}\right)$ at the horizontal distance of $44 \mathrm{~mm}$ at the measurement point of 1 while the corresponding maximum heat transfer coefficient at the same distance at the same measurement point of the simulation result provides the value of 1.69 $\mathrm{kW} / \mathrm{m}^{2} \mathrm{~K}$ with the deviation of $17.3 \%$. The minimum value shown by the experimental result has a value of 0.145 $\mathrm{kW} / \mathrm{m}^{2} \mathrm{~K}$ which meets the agreement with the minimum value among all of the simulation results at the same measurement point at the lowest edge of the measurement point of the plate at the distance of $4 \mathrm{~mm}$ respectively with the deviation of $28.9 \%$.

Therefore, the overall comparison results between the experimental data and the simulation data concludes that the directional heat flux $\left(\mathrm{q}_{\mathrm{x}}\right)$ results at the left and right sides of the plate have almost identical trends for the both data whereas there is more or less deviations between the both results in terms of local heat transfer coefficient values at the front face of the plate with similar trends but the larger experimental values of almost every points of measurement are obtained as the results of comparison.

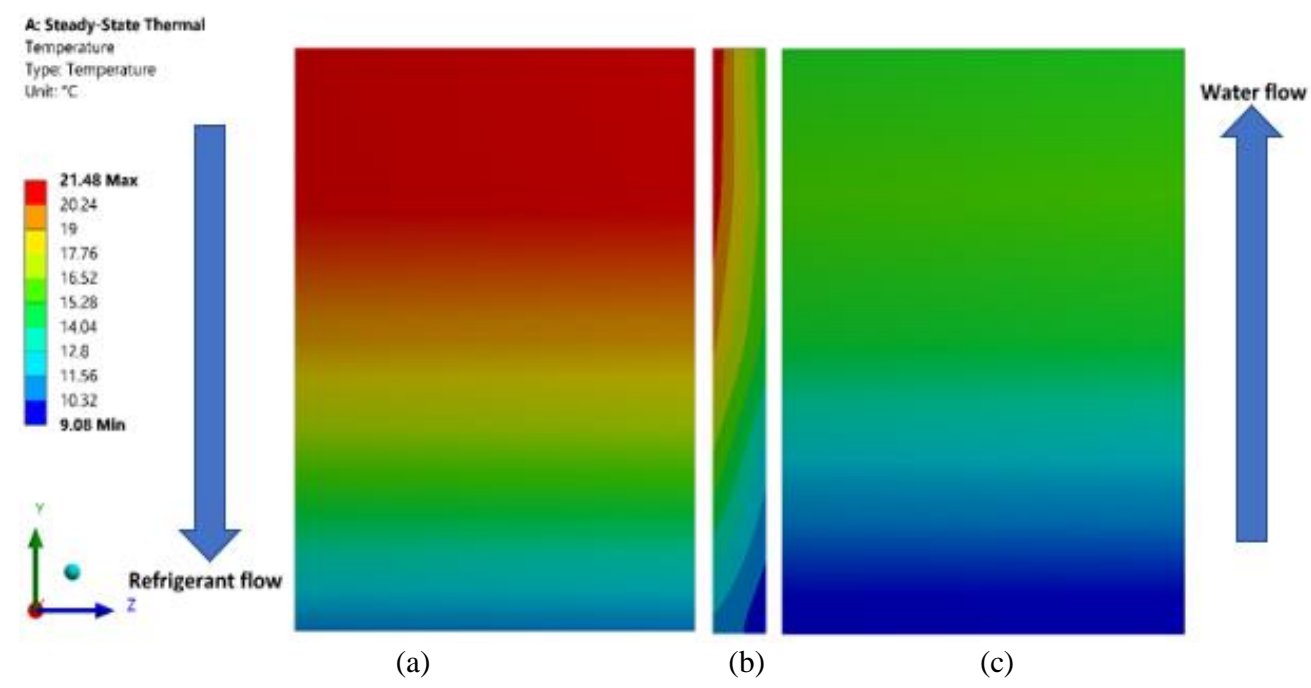

Figure 9. Contour of the temperature distributions of the plate (a) Refrigerant side, (b) Cross Section, (c) Water side 


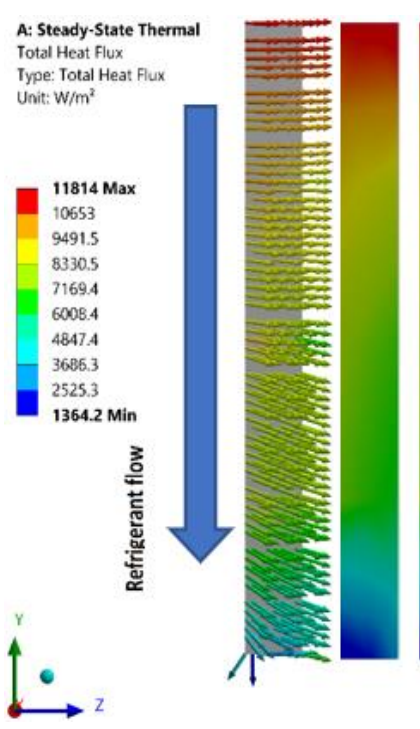

(a)

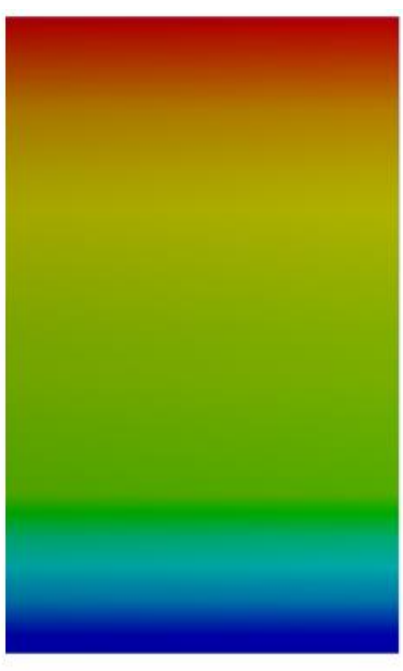

(c)

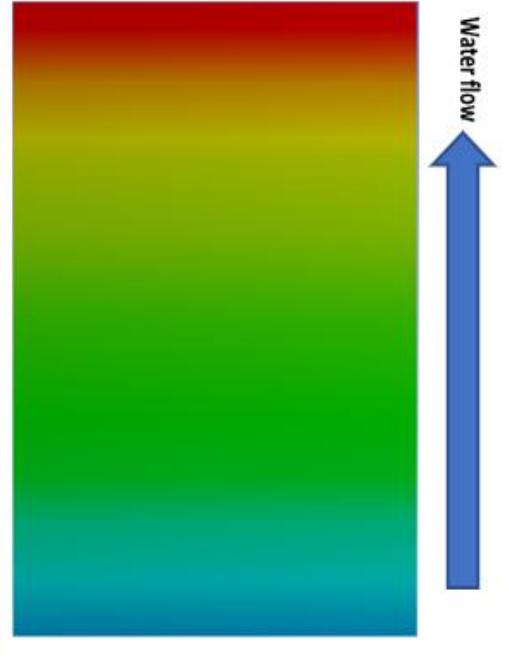

(d)

Figure 10. Contour of the total heat flux of the plate (a) Vector plot, (b) Cross section, (c) Refrigerant side (d) Water side

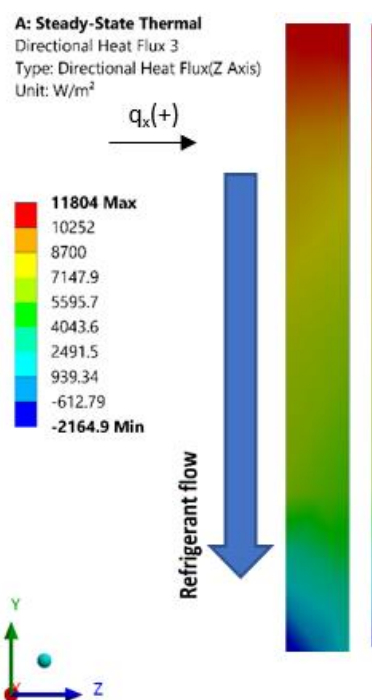

(a)

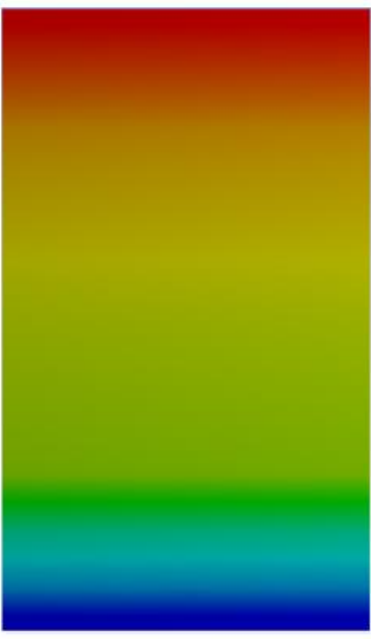

(b)
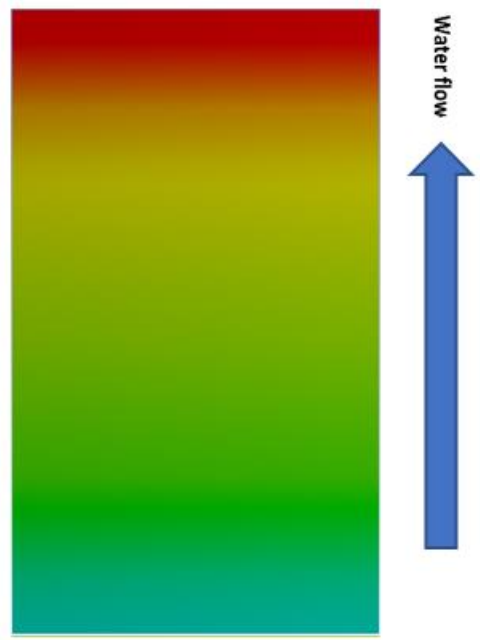

(c)

Figure 11. Contour of the $x$ component heat flux $\left(q_{x}\right)$ of the plate (a) Cross Section, (b) Refrigerant side, (c) Water Side

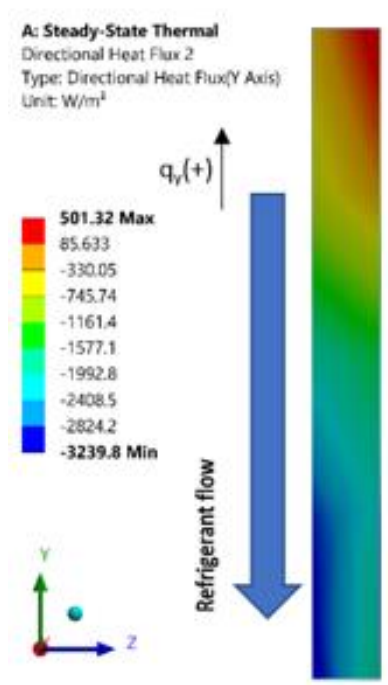

(a)

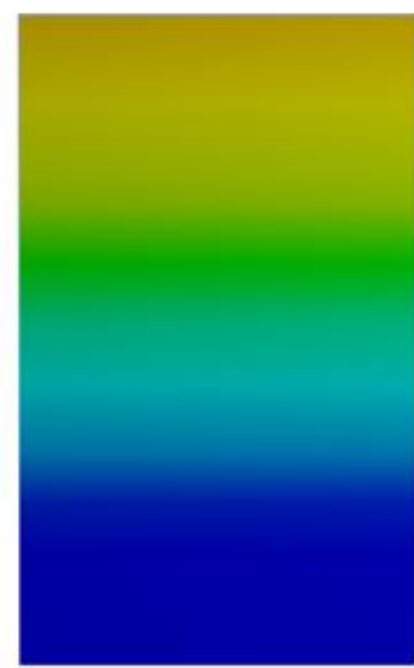

(b)

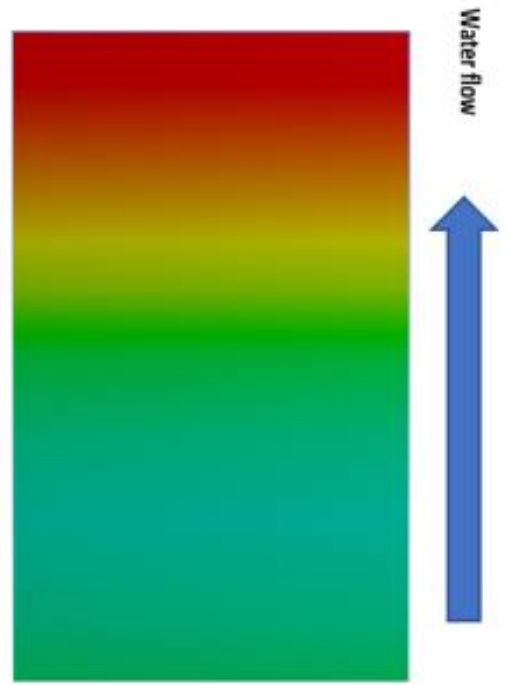

(c)

Figure 12. Contour plot of the $y$ component heat flux $\left(q_{y}\right)$ of the plate (a) Cross section, (b) Refrigerant side, (c) Water side 
The Directional Heat $\operatorname{flux}\left(q_{\mathrm{x}}\right)$ at The Thinner Left Side of The Plate

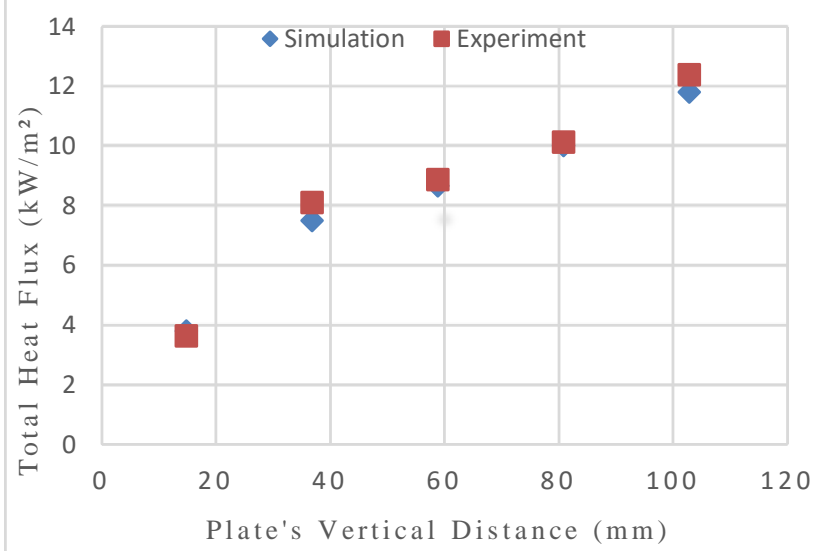

Figure 3. The comparison between the simulation and experimental results at the thinner left and right sides of the plate
The Directional Heat Flux $\left(q_{x}\right)$ at The Thinner Right Side of The Plate

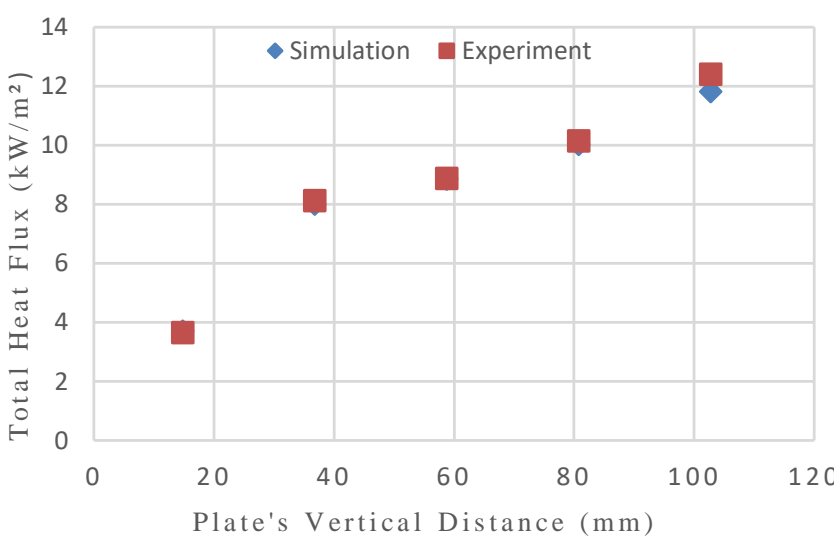

The Local heat Transfer Coefficient at measurement point 1

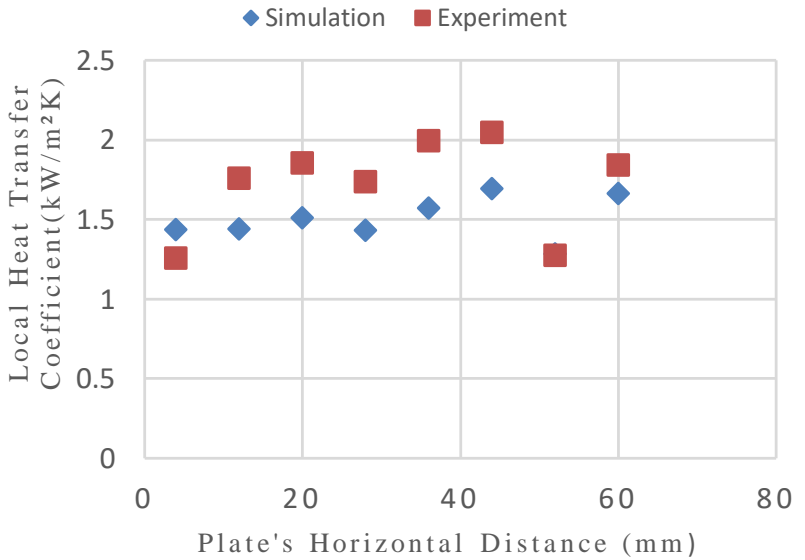

(a)

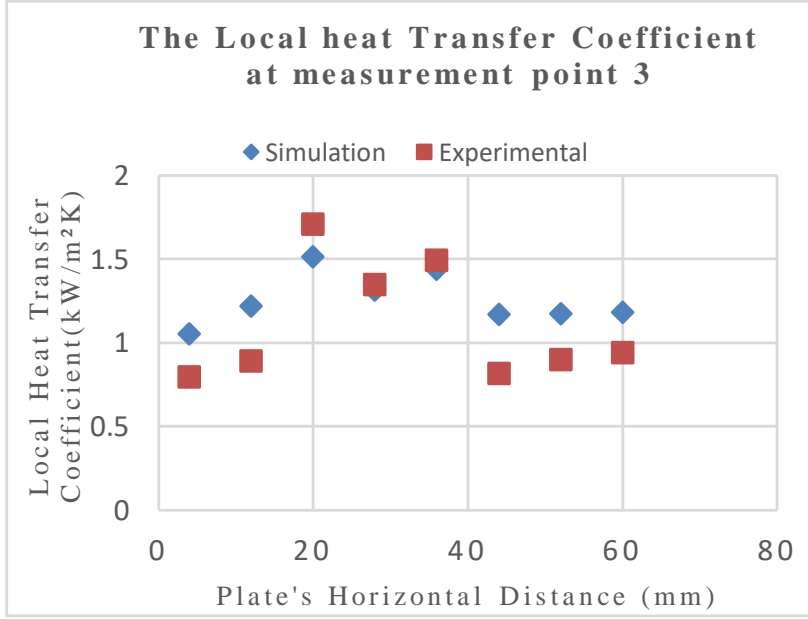

(c)
The Local heat Transfer Coefficient at measurement point 2

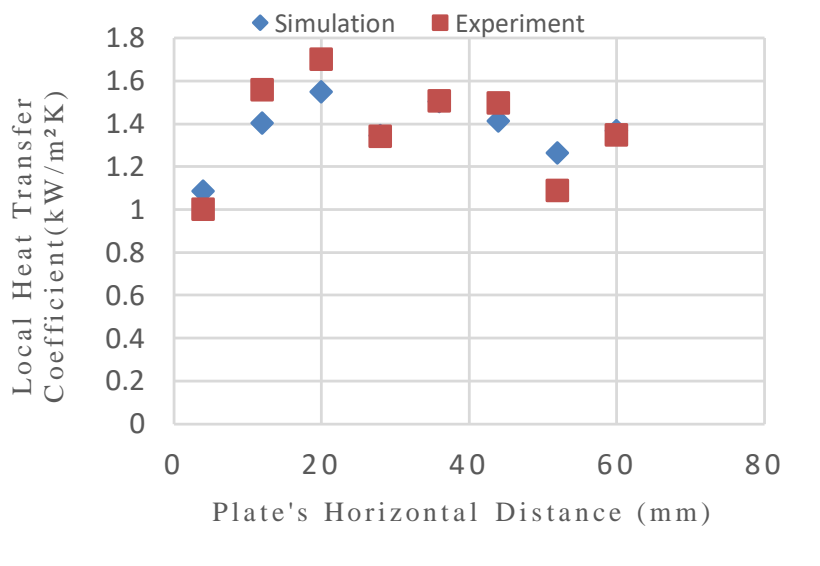

(b)

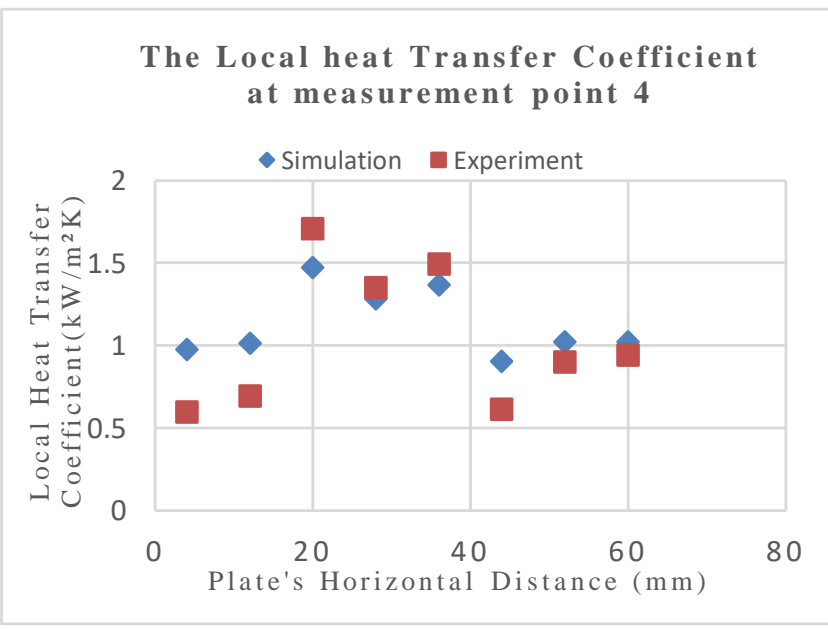

(d) 


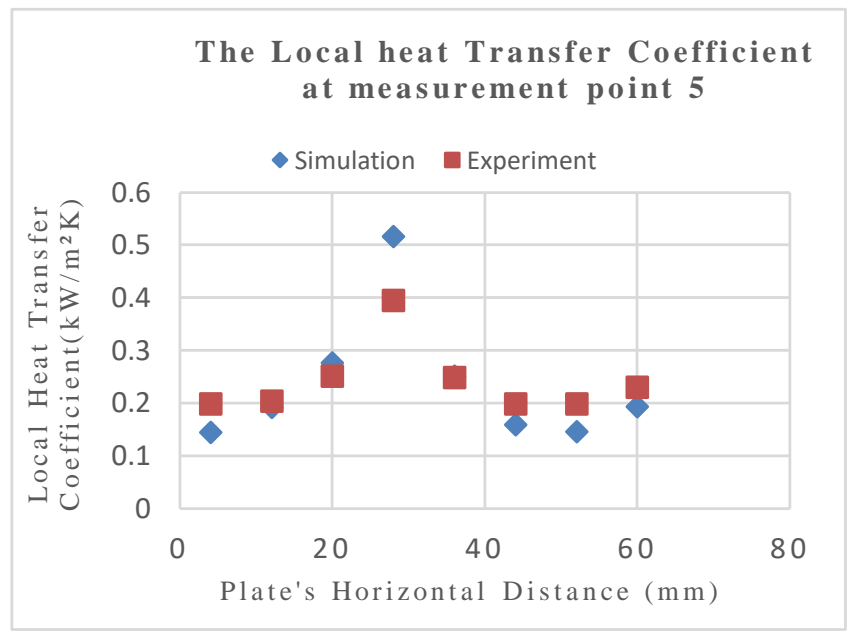

(e)

Figure 4. The Local heat Transfer Coefficient (a) At measurement point 1, (b) At measurement point 2, (c) At measurement point 3 , (d) At measurement point 4, (e) At measurement point 5

\section{Conclusion}

An experimental work was carried for the refrigerant R1234yf with the plate heat exchanger to obtain the local heat transfer coefficients in the PHEs for condensation experiment and the analysis was investigated and validated by the assistance of the simulation model developed in ANSYS FLUENT 19.1 R1 based on the temperature inputs obtained by the experiments. The summary of the analysis is shown below.

- The overall directional vector of the total heat flux across the plate tends to flow from the upper side of the plate to the lower side of the plate and this effect can be seen clearly in the simulation results.

- The validation results of the directional $x$ component heat flux at the left and right sides of the plate results in nearly identical trends at the measurement points from top to bottom vertically.

- For the local heat transfer coefficients comparison between the experimental and the simulation data show the similar trends with the experimental values mostly larger than the values received by the simulation model for the selected measurement points at the front face of the plate.

\section{Acknowledgements}

The New Energy and Industrial Technology Development Organization (NEDO), Japan supports the sponsorship for this study.

\section{References}

[1] M. S. Mahmud, K. Kariya, and A. Miyara, "Local Condensation Heat Transfer Characteristics of Refrigerant R1234ze(E) Flow Inside a Plate Heat Exchanger," Int. J. Air-Conditioning Refrig., vol. 25 , no. $1,2017$.

[2] V. Grabenstein and S. Kabelac, "Experimental Investigations and Modelling of Condensation in Plate Heat Exchangers," in International Heat Transfer Conference (IHTC), pp. 135-142.

[3] R. L. Amalfi, F. V. Farahani, and J. R. Thome, "Flow Boiling and Frictional Pressure Gradients in Plate Heat Exchangers. Part 1: Review and Experimental Database," Int. J. Refrig., vol. 61, pp. 166-184, 2016.

[4] R. L. Amalfi, F. Vakili-Farahani, and J. R. Thome, "Flow Boiling and Frictional Pressure Gradients in Plate Heat Exchangers. Part 2: Review and Experimental Database," Int. J. Refrig., vol. 61, pp. 165-203, 2016.
[5] Z. H. Ayuba, T. S. Khanb, S. Salamb, K. Nawazc, A. H. Ayub, and M. S. Khand, "Literature Survey and a Universal Evaporation Correlation for Plate Type Heat Exchangers," Int. J. Refrig., vol 99, pp. 408-418, 2019.

[6] B. Thonon, R. Vidil, and C. Marvillet, "Plate Heat Exchangers: Research and Developments," J. Enhanc. Heat Transf., vol. 24, no. $1-6,2017$.

[7] X. Tao and C. A. I. Ferreira, "Heat Transfer and Frictional Pressure Drop During Condensation in Plate Heat Exchangers: Assessment of Correlations and a New Method," Int. J. Heat Mass Transf., vol 135, pp. 996-1012, 2019.

[8] V. Grabenstein and S. Kabelac, "Experimental and Theoretical Analysis of the Local Condensation Heat Transfer in a Plate Heat Exchanger," in Journal of Physics: Conference Series, 2012, vol 395.

[9] Y. Jia, C. Wang, Z. Chang, W. Li, and C. Zhang, "Heat Transfer Modelling of Plate Heat Exchanger in Solar Heating System," vol. 7, pp. 426-447.

[10] O. J. Kwon, B. H. Shon, and Y. T. Kang, "Experimental Investigation on Condensation Heat Transfer and Pressure Drop of a Low GWP Refrigerant R-1233zd(E) in a Plate Heat Exchanger," Int. J. Heat Mass Transf., pp. 1009-1021, 2019.

[11] D.-H. Han, K.-J. Lee, and Y.-H. Kim, "The Characteristics of Condensation in Brazed Plate Heat Exchangers with Different Chevron Angles," J. Korean Phys. Soc., vol. 43, no. 1, pp. 66-73, 2003.

[12] R. N. Taktashev and T. S. I. F. A. Yerokhin, "Calculation of Heat Transfer in Case of Freon Condensation in Plate Condenser Channels," APRN J. Eng. Appl. Sci., vol. 11, no. 1, 2016.

[13] E. M. Djordjević, S. Kabelac, and S. P. Šerbanović, "Heat Transfer Coefficient and Pressure Drop During Refrigerant R-134a Condensation in a Plate Heat Exchanger," Chem. Pap., vol. 62, pp. 78-85, 2008

[14] G. A. Longo, A. Gasparella, and R. Sartori, "Experimental Heat Transfer Coefficients during Refrigerant Vaporisation and Condensation Inside Herringbone-type Plate Heat Exchangers with Enhanced Surfaces," Int. J. Heat Mass Transf., vol. 47, pp. 41254136, 2004.

[15] W. S. Kuo, Y. M. Lie, Y. Y. Hsieh, and T. F. Lin, "Condensation Heat Transfer and Pressure Drop of Refrigerant R410a Flow in a Vertical Plate Heat Exchanger," Int. J. Heat Mass Transf., vol. 48, pp. 5205-5220, 2005.

[16] A. Jokar, S. J. Eckels, M. H. Hosni, and T. P. Gielda, "Condensation Heat Transfer and Pressure Drop of Brazed Plate Heat Exchangers using Refrigerant R134a," J. Enhanc. Heat Transf., vol. 11, pp. 161-182, 2004.

[17] H. D. Baehr and K. Stephan, Heat and Mass Transfer. Berlin Springer, 1998

[18] J. G. Collier, Convective Boiling and Condensation, 2nd ed. New York: McGraw-Hill, 1981 
[19] V. S. Gullapalli and B. Sundén, "CFD Simulation of Heat Transfer and Pressure Drop in Compact Brazed Plate Heat Exchangers," $J$. Heat Transf. Eng., vol. 35, no. 4, pp. 358-366, 2014.
[20] A. K. Tiwari, P. Ghosh, J. Sarkar, H. Dahiya, and J. Parekh, "Numerical Investigation of Heat Transfer and Fluid Flow in Plate Heat Exchanger using Nanofluids," Int. J. Therm. Sci., vol. 85, pp. 93-103, 2014. 